\title{
Argininosuccinic aciduria
}

INSERM

\section{Source}

INSERM. (1999). Orphanet: an online rare disease and orphan drug data base.

Argininosuccinic aciduria. ORPHA:23

Argininosuccinic aciduria (ASA) is a disorder of urea cycle metabolism most commonly characterized by either a severe, neonatal-onset form that manifests with hyperammonemia accompanied with vomiting, hypothermia, lethargy and poor feeding in the first few days of life, or late-onset forms (any age outside the newborn period) that manifest with stress or infection-induced episodic hyperammonemia or, in some, behavioral abnormalities and/or learning disabilities. Patients often manifest liver dysfunction. 